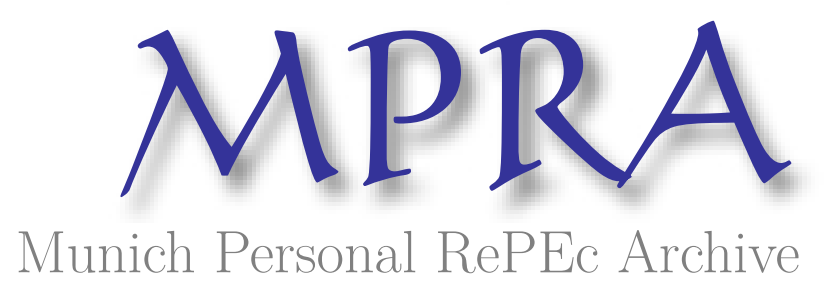

The dynamics of national innovation systems: a panel cointegration analysis of the coevolution between innovative capability and absorptive capacity

Fulvio, Castellacci and Jose Miguel, Natera

June 2011

Online at https://mpra.ub.uni-muenchen.de/31583/

MPRA Paper No. 31583, posted 15 Jun 2011 17:30 UTC 


\title{
The Dynamics of National Innovation Systems: A Panel Cointegration Analysis of the Coevolution between Innovative Capability and Absorptive Capacity
}

\author{
Fulvio Castellacci* $^{*}$ and Jose Miguel Natera ${ }^{\dagger}$ \\ * Norwegian Institute of International Affairs (NUPI), Oslo, Norway. E-mail: fc@ nupi.no \\ ${ }^{\dagger}$ University Complutense, Madrid, Spain. E-mail: jm.natera@pdi.ucm.es
}

This version: June 2011

\begin{abstract}
This paper puts forward the idea that the dynamics of national innovation systems is driven by the coevolution of two main dimensions: innovative capability and absorptive capacity. The empirical analysis employs a broad set of indicators measuring national innovative capabilities and absorptive capacity for a panel of 98 countries in the period 1980-2008, and makes use of panel cointegration analysis to investigate long-run relationships and coevolution patterns among these variables. The results indicate that the dynamics of national systems of innovation is driven by the coevolution of three innovative capability variables (technological output, scientific output, innovative input), on the one hand, and three absorptive capacity factors (income per capita, infrastructures and international trade), on the other.
\end{abstract}

Keywords: national systems of innovation; innovative capability; absorptive capacity; economic growth and development; coevolution; panel cointegration analysis.

JEL codes: $\mathrm{O} 1, \mathrm{O} 3, \mathrm{O} 4$ 


\section{Introduction}

The study of national innovation systems (NIS) has attracted considerable attention in the last two decades (Lundvall, 2007). While a substantial amount of research has been devoted to the investigation of cross-country differences in technological capabilities and the related institutional and policy framework, much less attention has so far been given to the analysis of the dynamics of national systems over time.

This is unfortunate, since evolution and change represent indeed key aspects of Schumpeterian research, which did in fact constitute some of the crucial motivations for the original development of the NIS approach. The lack of focus on dynamic aspects is partly explained by the non-availability of time series data for a sufficiently long period of time, and partly by the analytical and methodological difficulties that are faced when it comes to model and empirically analyse the dynamics of complex evolving systems (Foster, 1991).

The Schumpeterian literature on innovation and economic growth does however provide important insights and key building blocks for developing an analytically stronger framework to study NIS dynamics. First, idea-based new growth models point out the important role of national innovation capability for the growth of the economic system (Romer, 1990; Furman, Porter and Stern, 2002). Secondly, technology-gap models highlight the important role played by countries' absorptive capacity for imitation-based catching up, and show the large set of factors that contribute to define a country's absorptive capacity (Abramovitz, 1986; Verspagen, 1991; Godinho et al., 2006; Fagerberg and Srholec, 2008).

Most of the empirical literature on innovation and growth, though, has so far neglected the study of two important issues. The first is that, while a substantial amount of research has been devoted to the analysis of the impacts of innovation on economic growth, the investigation of the determinants and drivers of national innovative activities, has so far received only limited attention (Castellacci, 2011; Filippetti and Peyrache, 2011). Secondly, the applied literature on innovation and growth has typically focused on the cross-country comparative aspect ("why growth rates differ across countries") and often neglected the time series properties of the process of technological change and economic development. In short, the existing literature provides only limited insights on the drivers of national systems of innovation and the mechanisms that may explain their evolution and growth over time.

Motivated by this important gap, this paper adopts a time series perspective and shifts the focus to the analysis of the drivers of national innovation systems over time. In a nutshell, the paper puts forward the idea that innovative capability and absorptive capacity are linked by a set of 
two-way dynamic relationships, and that their process of coevolution represents a key mechanism driving the growth of national systems in the long-run.

Our empirical analysis makes use of a broad set of indicators measuring national innovative capabilities and absorptive capacity for a panel of 98 countries in the period 1980-2008. The empirical methodology that we adopt is rooted in the panel cointegration approach, which represents a recent extension of the time series cointegration analysis of non-stationary variables to the panel data context (Breitung and Pesaran, 2008). The cointegration methodology has an inherent ability to uncover dynamic relationships among variables that coevolve over time, and we therefore argue that it constitutes a natural platform for investigating the long-run dynamics of national systems of innovation.

The empirical results indicate that innovative capability and absorptive capacity variables are indeed linked by a set of long-term structural relationships over the period 1980-2008. Specifically, the dynamics of national systems of innovation is driven by the coevolution of two sets of factors: technological output, scientific output and innovative input, on the one hand, and income per capita, infrastructures and international trade, on the other.

The paper is organized as follows. Section 2 provides a brief review of the literature, section 3 presents the theoretical framework and hypotheses, section 4 points out the data and indicators, section 5 introduces the econometric method, section 6 discusses the empirical results, and section 7 highlights some of the main findings and possible future extensions of the work.

\section{Literature review}

National innovation systems (NIS) are key drivers of economic growth and competitiveness. The study of NIS focuses on the main components of the system, such as private firms and public organizations, and investigates their mutual interactions as well as their relationships with the social and institutional framework in which the system is embedded (Lundvall, 2007). The study of the dynamics and evolution of national systems provided one of the original motivations for the development of this approach. However, the focus on long-run dynamics and historical transformations was mainly developed in a branch of qualitative and historical case studies research (Nelson, 1993; Edquist and Hommen, 2008; Lundvall et al., 2009). By contrast, quantitative and modelling oriented contributions in this field have not yet provided a consistent and fully-fledged analysis of the complex set of factors that drive the dynamics of national systems in the long-run. This is partly due to the lack of a strong analytical framework able to describe the dynamics of NIS as complex evolving systems, and, correspondingly, it is 
also related to the lack of quantitative empirical tools (data, indicators and methods) that would make it possible to carry out an empirical investigation of such a theory of complex innovation system dynamics.

Important branches of the literature on innovation and economic growth do however provide key theoretical insights and empirical results on some of the main factors that are relevant to describe the long-run evolution of a national innovation system and its relationships to economic performance.

The first is new growth theory, and in particular Romer's (1990) idea-based growth model. This seminal work points out that the growth of a country's knowledge stock, its innovation dynamics, depends on a few key factors such as the size of its research sector as well as the productivity of the latter, which defines the extent to which innovation input and investments are turned into innovation output and economic performance. The concept of innovative capability, despite its highly stylized character, defines a first key dimension to study the evolution of NIS. Furman, Porter and Stern (2002) define it as "the ability of a country to produce and commercialize a flow of innovative technology over the long term" (2002: 899). Romer's (1990) model has been highly influential and has inspired the development of an entire class of idea-based new growth models. Nevertheless, empirical analyses of this type of model have mostly focused on the main prediction of its reduced form on the relationship between the size of the research sector and the country's economic performance, and have, by contrast, typically neglected the investigation of its structural form, and specifically of the determinants of a country's innovation dynamics and its transformations in the long-run (Castellacci, 2007).

Secondly, a large modelling and empirical literature has focused on the process of international knowledge diffusion and investigated the set of factors that affect the extent to which a national system is able to grow and catch up with the technological frontier by means of international learning and imitation activities. This approach was originally inspired by the work of economic historians such as Landes, Gerschenkron and Abramovitz, which, by focusing on historical case studies of the technological catch up process, pointed out that international knowledge diffusion is a complex and demanding process, and investigated the set of factors that are necessary for imitation-based technological development. This set of factors, in a nutshell, defines the absorptive capacity of a country.

\footnotetext{
${ }^{1}$ Furman, Porter and Stern (2002), more precisely, used the expression "national innovative capacity", instead of the term innovative capability that is adopted throughout this paper.
} 
According to Abramovitz (1986; 1994), absorptive capacity may refer to both technoeconomic characteristics (technological congruence) such as "the resource availabilities, factor supplies, technological capabilities, market scales and consumer demands", as well as socioinstitutional conditions (social capability) like "countries' level of education and technical competence, the commercial, industrial and financial institutions that bear on their abilities to finance and operate modern, large-scale business, and the political and social characteristics that influence the risks, the incentives and the personal rewards of economic activity" (Abramovitz, 1994: 24).

Inspired by these original insights, theoretical models in the technology-gap (or distance-tofrontier) tradition have developed a more stylized notion of absorptive capacity, and often focused on human capital as the single most important factor shaping a country's capability to imitate and absorb foreign advanced technologies (Nelson and Phelps, 1966; Verspagen, 1991; Benhabib and Spiegel, 1994; Papageorgiou, 2002; Stokke, 2004).

On the other hand, empirical works in this tradition have typically followed a growthregression econometric approach, and shown the large variety of factors, of both a technoeconomic and socio-institutional nature, that affect convergence and divergence patterns in broad cross-country samples (e.g. Fagerberg and Verspagen, 2002; Fagerberg et al., 2007; Fagerberg and Srholec, 2008; Castellacci, 2008). ${ }^{2}$ Most of this empirical research, however, has so far focused on the cross-country comparative aspect ("why growth rates differ") and mostly neglected the time series dimension and the analysis of the dynamics of the technological catch up and economic growth process over time.

A more explicit investigation of the dynamic dimension is provided by a recent class of theoretical models in the distance-to-frontier tradition, which point out that the existence of threshold externalities may explain the cumulative nature of the process of technological accumulation and economic growth in the long-run. Specifically, threshold externalities models are based on the idea that the interactions between countries' R\&D and innovation activities, on the one hand, and human capital and imitation activities, on the other, may generate different country clubs, and explain the transition of each national system from one stage of development to a more advanced one (Azariadis and Drazen, 1990; Howitt, 2000; Galor and Weil, 2000; Galor, 2005; Howitt and Mayer-Foulkes, 2005; Acemoglu et al., 2006; Iacopetta, 2010). In particular, these models argue that the key to explain countries' shift from an imitation to an innovation stage is the return to investment in human capital: this tends to grow during the development process, thus making it progressively more profitable for

\footnotetext{
${ }^{2}$ See overview of this empirical literature in Fagerberg (1994) and Gong and Keller (2004).
} 
individuals to invest in education and, hence, sustaining further technological progress in the future. Despite its highly stylized character, this idea provides an important step forward in the theory of innovation and growth, since it implicitly points out the two-way interactive relationship that links the dynamics of innovation and absorptive capacity in the long-run. This brief review of the literature leads to point out four major challenges ahead for research in this field. These four aspects represent the main motivations for the analysis carried out in the present paper.

1. A time series perspective. Most empirical research on national innovation systems and economic growth has so far adopted an explicitly comparative perspective - focusing on crosscountry differences in technological capabilities - and largely neglected the time series dimension. The investigation of the dynamics and time series properties of the long-run evolution of national innovation systems is a key challenge ahead in the field, which should complement and inform cross-country comparative research.

2. The dynamics and determinants of innovative capability. An exceptional amount of research has been devoted to the study of the determinants of GDP and income per capita, and in particular to the role of innovation for the growth and development process. By contrast, only a limited number of studies have empirically investigated the dynamics of innovative capability over time and the main factors that may explain its long-run evolution (Furman, Porter and Stern, 2002; Varsakelis, 2006; Filippetti and Peyrache, 2011). This is a crucial task for future research in this field.

3. The dynamics and multifaceted nature of absorptive capacity. Although the concept of absorptive capacity was initially meant to define a broad and multidimensional set of capabilities, modelling and empirical exercises have often provided a rather stylized and simplified operationalization of it. As recently argued by Archibugi and Coco (2004), Godinho et al. (2006) and Fagerberg and Srholec (2008), it is indeed important to adopt a multifaceted description and measurement of the various factors that contribute to shape the absorptive capacity of nations. Further, it is crucial to investigate the dynamics and long-run evolution of absorptive capacity, rather than simply regarding it as a set of exogenous control factors in cross-country growth regression exercises. 
4. The coevolution between innovative capability and absorptive capacity. In the cross-country applied growth literature, innovation and imitation have typically been regarded as two distinct (albeit related) drivers of growth and catching up. However, adopting a time series perspective, it is important to investigate the existence of a two-way relationship (coevolution) that links together the dynamics of these dimensions in the long run.

\begin{abstract}
"Over time, there is a two-way interaction between the social capabilities required by technological best-practice and the development of those very capabilities. A country's ability to exploit the opportunities afforded by existing best practice is limited by its current capabilities. Capabilities, however, tend to develop in the directions to which the requirement of a leading technology point [...] Levels of general and technical education are raised and their content altered; legal codes are modified; corporate and financial institutions are established and people learn their modes of action. Moreover, experiences gained in the practice of a technology enhance the technical and managerial capabilities that serve it and thus support further advance along the same path. Such interaction, therefore, may for a time solidify a leader's position or, in the case of laggards, may work to counter the tendency that would otherwise exist for their relative growth rates to decline as catch-up proceeds" (Abramovitz, 1994: 25).
\end{abstract}

\title{
3. Model and hypotheses
}

This section provides the theoretical framework for our empirical analysis of the coevolution between countries' innovative capability and absorptive capacity. The model focuses on the time series dimension of the process of technological change, i.e. its objective is to provide a foundation for the empirical analysis of the dynamics of the national innovation system for a given country, rather than comparing the characteristics of different national systems in a static sense.

First, since many different factors contribute to define the innovative capability and absorptive capacity of nations, it is important to highlight the key set of variables on which our model will focus. Figure 1 shows our theoretical framework. The diagram provides a stylized representation of some of the main dimensions that define the dynamics of a national innovation system.

\section{Innovative capability:}

- Innovative input. This represents the total efforts and investments carried out by each country for R\&D and innovative activities (i.e. its innovation intensity).

- Scientific output. It denotes the result of research and innovation activities carried out by the public S\&T system (e.g. scientific and technical publications). 
- Technological output. This is the total output of technological and innovative activities carried out by private firms (e.g. patents, new products).

\section{Absorptive capacity:}

- Income level. It defines the overall level of economic and social development of a country, and it is then an important factor to define its absorptive capacity.

- International trade. This represents the openness of the national system. The more open the system, the more capable to imitate foreign advanced knowledge (Gong and Keller, 2004).

- Human capital. This is the key absorptive capacity variable typically emphasized by technology-gap models (see references in section 2).

- Infrastructures. A greater level and quality of infrastructures (e.g. network, transportation, distribution) increases the country's capability to absorb, adopt and implement foreign advanced technologies (Esfahani and Ramirez, 2003; Freeman, 2004; Castellacci, 2011).

- Quality of institutions and governance system. A better and more efficient governance system tends to increase the country's commitment to technological upgrading as well as its imitation capability (Varsakelis, 2006; Fagerberg and Srholec, 2008).

- Social cohesion and economic inequality. A national system with a greater level of social cohesion and within-country income equality is in general characterized by a higher degree of trust and knowledge sharing, hence supporting the pace of diffusion and adoption of advanced knowledge within the country (Arocena and Sutz, 2003; Weinhold and NairReichert, 2009).

\section{$<$ Figure 1 here >}

In econometric terms, we represent the dynamics of the national system as a vector autoregression model (VAR). Define $\mathbf{Y}$ as the vector of innovative capability variables listed above $\left[\mathrm{Y}_{1} ; \mathrm{Y}_{2} ; \mathrm{Y}_{3}\right], \mathrm{X}$ the vector of absorptive capacity variables $\left[\mathrm{X}_{1} ; \mathrm{X}_{2} ; \mathrm{X}_{3} ; \mathrm{X}_{4} ; \mathrm{X}_{5} ; \mathrm{X}_{6}\right]$, and $\boldsymbol{\varepsilon}$ a vector of nonautocorrelated disturbances. Then, the VAR model of order $p$ is defined as:

$$
\mathbf{Y}_{\mathrm{t}}=\boldsymbol{\mu}+\boldsymbol{\Omega}_{1} \mathbf{Y}_{\mathrm{t}-1}+\ldots .+\boldsymbol{\Omega}_{\mathrm{p}} \mathbf{Y}_{\mathrm{t}-\mathrm{p}}+\boldsymbol{\Psi}_{1} \mathbf{X}_{\mathrm{t}-1}+\ldots \ldots+\boldsymbol{\Psi}_{\mathrm{p}} \mathbf{X}_{\mathrm{t}-\mathrm{p}}+\boldsymbol{\varepsilon}_{\mathrm{t}}
$$


This is a system of $m$ equations, each of which models a given time series variable $\mathrm{Y}_{\mathrm{mt}}$ as a function of the lagged values of all the variables in the vector $\mathbf{Y}$, the lagged values of the set of variables $\mathbf{X}$, and the disturbance term. In other words, the $\mathrm{m}^{\text {th }}$ equation of the VAR system is given by:

$\mathrm{Y}_{\mathrm{mt}}=\mu_{\mathrm{m}}+\sum_{\mathrm{j}}\left(\boldsymbol{\Omega}_{\mathrm{j}}\right)_{\mathrm{m} 1} \mathrm{Y}_{1, \mathrm{t}-\mathrm{j}}+\sum_{\mathrm{j}}\left(\boldsymbol{\Omega}_{\mathrm{j}}\right)_{\mathrm{m} 2} \mathrm{Y}_{2, \mathrm{t}-\mathrm{j}}+\ldots \ldots+\sum_{\mathrm{j}}\left(\boldsymbol{\Omega}_{\mathrm{j}}\right)_{\mathrm{mM}} \mathrm{Y}_{\mathrm{M}, \mathrm{t}-\mathrm{j}}+\sum_{\mathrm{j}}\left(\boldsymbol{\Psi}_{\mathrm{j}}\right)_{\mathrm{m} 1} \mathrm{X}_{1, \mathrm{t}-\mathrm{j}}+$ $+\sum_{\mathrm{j}}\left(\boldsymbol{\Psi}_{\mathrm{j}}\right)_{\mathrm{m} 2} \mathrm{X}_{2, \mathrm{t}-\mathrm{j}}+\ldots . .+\sum_{\mathrm{j}}\left(\boldsymbol{\Psi}_{\mathrm{j}}\right)_{\mathrm{mM}} \mathrm{Y}_{\mathrm{M}, \mathrm{t}-\mathrm{j}}+\varepsilon_{\mathrm{mt}}$

Given this VAR representation, we may then point out the three general propositions that will be investigated in our empirical analysis.

\section{Proposition 1. The internal dynamics of innovative capability.}

The dynamics of the innovative capability is driven by the coevolution of the three factors that define it, namely innovative input, scientific output and technological output.

By coevolution we mean that we expect to find a set of two-way relationships linking together the set of variables in the vector $\mathbf{Y}$ of our VAR (p) model. Specifically, and in line with the innovation literature, we argue that: (a) the innovative input and intensity is expected to affect the technological and scientific output (input-output mechanisms); in turn, (b) the technological and scientific output will have feedback effects on the dynamics of innovative input (cumulativeness of technological progress). While these two relationships are well-known and widely acknowledged in the field, the novelty of this proposition is that we specifically postulate the existence of a two-way self-sustaining dynamic relationship (coevolution) that drives the growth of innovative capability over time.

\section{Proposition 2. The internal dynamics of absorptive capacity.}

The dynamics of the absorptive capacity is driven by the coevolution of the six dimensions that define it.

In the VAR representation, this proposition implies that we expect the components of the vector $\mathbf{X}$ to be linked together by a set of two-way dynamic relationships. Many such relationships have previously been investigated in different branches of research and particularly in the applied growth and development literature, which has extensively documented the relationships between some of these variables (income level, international 
trade, human capital, infrastructures, quality of institutions and governance system, social cohesion and economic inequality). Our specific point here is to emphasize the joint dynamics of these factors, i.e. to investigate the process of coevolution (two-way dynamic relationships) that drives the growth of absorptive capacity over time.

\section{Proposition 3. The coevolution between innovative capability and absorptive capacity.}

Innovative capability and absorptive capacity coevolve over time, i.e. these two dimensions are linked together by a set of two-way dynamic relationships.

In terms of our VAR (p) model, this means that we expect the set of variables in the vector $\mathbf{Y}$ to be linked to the vector of variables $\mathbf{X}$ by a set of two-way dynamic relationships. The intuition is briefly pointed out as follows.

(a) On the one hand, innovation activity and results may sustain the growth of absorptive capacity over time. The reason is twofold. First, R\&D investments and innovative efforts may increase the agent's (country's) capabilities to imitate foreign advanced technologies (learning and capability effect). Secondly, the achievement of technological performance and commercial success tends to increase the country's pool of financial resources, some of which will be reinvested to increase its level of infrastructure, human capital or its institutional quality - hence raising the country's absorptive capacity in the future (success-breeds-success effect).

(b) On the other hand, the growth of absorptive capacity may in turn boost innovation dynamics over time. The reason is twofold. First, an increase in absorptive capacity, and in particular human capital, infrastructures and openness, is likely to strengthen the productivity of the country's R\&D sector (productivity effect). Secondly, the development of the country's institutional and governance quality, which is an inherent manifestation of the process of upgrading of absorptive capacity, may systematically increase the amount of resources that the system will devote to $\mathrm{R} \& \mathrm{D}$ activities, e.g. because it enhances the country's policy commitment to an increased level of innovation intensity (policy effect). 


\section{Data and indicators}

Our empirical analysis makes use of the CANA database, a newly released cross-country panel dataset containing a large number of indicators for the period 1980-2008 (Castellacci and Natera, 2011). The novelty of the database is that it provides full information for the whole set of country-year observations, i.e. it contains no missing value. The dataset has been constructed by combining together indicators available from a number of existing crosscountry data sources, and then applying the method of multiple imputation recently proposed by Honaker and King (2010). The CANA database, along with the sources and definitions of the indicators and a description of the construction methodology, can be downloaded at the web address: http://portal.ucm.es/web/grinei/cana-data.

Specifically, this paper focuses on a sample of 98 countries (listed in Appendix 1) and a set of nine selected indicators, which are pointed out as follows.

\section{Innovative capability:}

- Innovative input. R\&D expenditures as a percentage of GDP.

- Scientific output. Number of scientific and technical journal articles per million people.

- Technological output. Number of patents registered at the US Patent and Trademark Office per million people.

\section{Absorptive capacity:}

- $\quad$ Income and development level. GDP per capita, purchasing power parity.

- $\quad$ International trade. Openness: (Import + Export) / GDP.

- Human capital. Tertiary education: tertiary enrolment ratio.

- Infrastructures. Number of kilowatt of electricity consumed per hour per capita.

- Quality of institutions and governance system. Corruption Perception Index (Transparency International), ranging from 0 (High Corruption) to 10 (Low Corruption). 
- Social cohesion and economic inequality. Gini Index (within-country income inequalities).

\section{Econometric method}

Panel cointegration analysis is a recent field in econometrics that extends time series cointegration analysis to a panel data setting. The approach has recently found an increasing number of applications in different fields of economics, although it has not been used yet within the field of innovation and growth. The cointegration methodology has an inherent ability to uncover dynamic relationships among variables that coevolve over time, and we therefore argue that it constitutes a natural platform for investigating the long-run dynamics of national systems of innovation. ${ }^{3}$

Within a time series context, the main idea of the cointegration approach can be summarized as follows. Suppose we are interested in the relationship between the two variables $V_{t}$ and $W_{t}$, and that both of these are characterized by an increasing trend over time (as it is typically the case for many macroeconomic time series). If we take first differences of these variables - as it was commonly done in the traditional approach before cointegration analysis was introduced - the variables could be treated by means of standard techniques for stationary time series analysis. ${ }^{4}$ However, by removing the trend from these series, we would not any longer be able to investigate the existence of a long run relationship between $\mathrm{V}_{\mathrm{t}}$ and $\mathrm{W}_{\mathrm{t}}$.

This idea provided the main motivation for developing the time series cointegration approach, whose key insight is precisely to analyse the relationships between non-stationary time series by looking both at their long-run equilibrium relationship as well as the process of short-run adjustment (Engle and Granger, 1987). More precisely, if two or more variables are integrated of the same order (e.g. they are both I(1) series), there might exist a linear combination of them whose residuals are stationary - in other words the two series are not stationary but one (or

\footnotetext{
${ }^{3}$ An important antecedent of our approach is the work of Foster (1991), which already two decades ago discussed the suitability of time series cointegration analysis and error correction models for evolutionary analyses of technological change and economic growth. Recent applications of the panel cointegration approach have been presented, among others, in the field of energy economics (Costantini and Martini, 2010) and trade and FDI (Krammer, 2010).

${ }^{4}$ A time series that becomes stationary after first differencing is said to be $I(1)$, i.e. integrated of order 1 . By definition, an $\mathrm{I}(0)$ series is stationary in levels.
} 
more) linear combination of them is. If this is the case, the variables are said to be cointegrated.

To illustrate, figure 2 plots the time path of some of the indicators of innovative capability and absorptive capacity described in the previous section for a few selected countries over the period 1980-2008. ${ }^{5}$ It is clear from the figure that most of these variables have a common time trend, and it is therefore reasonable to investigate the hypothesis that they coevolve over time linked by some structural long-term relationship (as argued in the three propositions presented in section 3).

\section{$<$ Figure 2 here $>$}

The extension of this time series approach to a panel data context is relatively recent (see overview in Breitung and Pesaran, 2008). The use of panel datasets, by increasing substantially the number of observations in the sample, makes it possible to strengthen the power of cointegration tests, while at the same time enabling to deal with the issue of cross-country heterogeneity by including fixed effects and country-specific trends in the econometric specification.

More specifically, the empirical methodology adopted in this paper consists of the following four steps. First, since cointegration analysis can by definition only be used to study the relationships between time series variables that have the same order of integration, we start by carrying out a battery of panel unit root tests (Levin, Lin and Chu; Breitung; Im, Pesaran and Shin; augmented Dickey-Fuller; Phillips-Perron), in order to make sure that our variables are stationary after removing the time trend by first-differencing (i.e. they are I(1) series).

Secondly, we investigate the existence of a long-run equilibrium relationship between our variables of interest by means of the Pedroni cointegration test, which adopts ADF and PP-like specifications and extends them to a panel dataset by looking at both the within- and betweendimension of the panel. We repeat both the first and the second step for 10 different lags (from 1 to 10), in order to make sure that the results are robust and not too sensitive to the lag specification that is used for each test (which is a well-known problem for this type of time series analyses). If the Pedroni test results are significant, this means that there exists one (or more) linear combination of our non-stationary variables that has stationary residuals, or in simpler terms that there exists a long-run equilibrium relationship among the variables. The

\footnotetext{
${ }^{5}$ Notice that for the construction of this figure the indicators have been standardized, so that variables measured on a different scale can be reported in the same graph.
} 
nature, strength and direction of this long-run relationship is then investigated in the third and fourth steps, which represent the crucial phase of our empirical analysis.

The third step is the estimation of a panel vector error correction model (VECM). This model is useful because it makes it possible to estimate both the long-run equilibrium relationship among the variables as well as the short-run adjustment process by which they respond to external shocks that deviate from their long-run equilibrium path.

In order to explain the main idea and intuition of this model, let us first derive it in a time series bivariate context, and then extend it to a panel multivariate setting. Take first a simplified version of our VAR (p) model specified in equation 1 (section 3), i.e. only considering two variables $\mathrm{Y}_{\mathrm{t}}$ and $\mathrm{X}_{\mathrm{t}}$ and one lag (this may also be seen as an autoregressive distributed lag model, ARDL $(1,1))$. By taking first-differences and rearranging some of the terms, the ARDL $(1,1)$ model can be written in the error-correction form:

$\Delta \mathrm{Y}_{\mathrm{t}}=\alpha\left(\mathrm{Y}_{\mathrm{t}-1}-\theta \mathrm{X}_{\mathrm{t}-1}\right)+\beta\left(\Delta \mathrm{X}_{\mathrm{t}}\right)+\varepsilon_{\mathrm{t}}$

In this specification, the parameter $\beta$ measures the long-term equilibrium relationship between the variables, whereas the term $\left(\mathrm{Y}_{\mathrm{it}-1}-\theta \mathrm{X}_{\mathrm{it}-1}\right)$ represents the so-called equilibrium error of the model, i.e. the extent to which the variables respond in the short-run to a deviation from their long-run path (the vector of parameters $\alpha$ thus measures the speed of adjustment that the system follows in the short term). Put it simply, in the context of our study, the parameter $\beta$ measures the long-term relationship between innovative capability and absorptive capacity, while $\alpha$ gives an indication of how rapidly (or slowly) each variable goes back to its long-run structural path in the presence of an external shock (e.g. a policy change).

Let us now extend this ECM formulation to the more general case that is considered in this paper, i.e. where we have a vector of innovation capability variables $\mathbf{Y}$, a vector of absorptive capacity variables $\mathbf{X}, p$ lags, and $n$ countries. The panel version of our VAR (p) model in equation 1 (section 3 ) is:

$\mathbf{Z}_{\mathrm{i}, \mathrm{t}}=\boldsymbol{\mu}_{\mathrm{i}}+\boldsymbol{\Phi}_{1} \mathbf{Z}_{\mathrm{i}, \mathrm{t}-1}+\ldots .+\boldsymbol{\Phi}_{\mathrm{p}} \mathbf{Z}_{\mathrm{i}, \mathrm{t}-\mathrm{p}}+\boldsymbol{\varepsilon}_{\mathrm{it}}$

where $\mathbf{Z}$ denotes the vector including all variables of our model $[\mathrm{Y} 1, . ., \mathrm{Y} 3, \mathrm{X} 1, \ldots, \mathrm{X} 6]$. The system can be rewritten in its panel VECM specification as:

$\Delta \mathbf{Z}_{\mathrm{i}, \mathrm{t}}=\boldsymbol{\mu}_{\mathrm{i}}+\boldsymbol{\Pi} \mathbf{Z}_{\mathrm{i}, \mathrm{t}-1}+\sum_{\mathrm{j}} \boldsymbol{\Gamma}_{\mathrm{j}} \Delta \mathbf{Z}_{\mathrm{i}, \mathrm{t}-\mathrm{i}}+\boldsymbol{\varepsilon}_{\mathrm{it}}$ 
where $\boldsymbol{\Pi}=\sum_{\mathrm{j}} \boldsymbol{\Phi}_{\mathrm{j}}-\mathbf{I}_{\mathrm{K}}$, and $\boldsymbol{\Gamma}_{\mathrm{j}}=-\sum_{\mathrm{j}} \boldsymbol{\Phi}_{\mathrm{j}}$. The system of equation represented by (6) is the one that we will estimate in the following section. As explained above, the parameters in $\boldsymbol{\Gamma}_{\mathrm{j}}$ measure the long-term (cointegration) relationships between our variables, whereas the set of parameters $\boldsymbol{\Pi}$ measure the short-run adjustment of each variable to its long-run equilibrium.

Finally, the fourth and final step of our methodology is to investigate the direction of causality, i.e. to analyse whether the long-term relationship identified by the VECM model between each pair of variables $Y_{t}$ and $X_{t}$ is a uni-directional type of causality $\left(Y_{t} \rightarrow X_{t}\right.$, or $\left.Y_{t} \leftarrow X_{t}\right)$ or rather bi-directional $\left(\mathrm{Y}_{\mathrm{t}} \leftrightarrow \mathrm{X}_{\mathrm{t}}\right)$. This is done by making use of Granger causality analysis, i.e. by carrying out, for each pair of variables included in the VECM model, a Granger block exogeneity test. Since the results of Granger causality analysis are typically quite sensitive to the lag specification that is adopted, for each pair of variables we carry out block exogeneity tests for 10 different lags (from 1 to 10), and, as explained in the next section, we only consider reliable those results for which we obtain significant evidence of a causal relationship for at least five of the 10 lag specifications.

To summarize, this four-step methodology provides an attempt to operationalize the concept of coevolution within a panel cointegration context. In our empirical analysis, the coevolution between two variables $Y_{t}$ and $X_{t}$ is meant to be characterized by two aspects: (1) there exists a long-run structural relationship that ties together the dynamics of these variables (cointegration); (2) there exist two-way causal relationships between them (Granger bidirectional causality). 


\section{Empirical results}

Table 1 presents the results of a large set of panel unit root tests (Levn, Lin \& Chu; Breitung; Im, Pesaran \& Shin; ADF; PP). Each test is repeated for all the nine variables included in the model and for ten different lags. The results clearly indicate that all variables in our panel of countries are I(1) series (trend stationary), thus confirming that it is appropriate to investigate the existence of cointegration relationships among them.

Next, the second step of our analysis is to carry out a set of Pedroni cointegration tests, which analyse the cointegration hypothesis for these nine variables in our panel of countries (and again repeating the exercise for ten different lags in order to check for the robustness of the results). Table 2 presents the results, which provide strong evidence suggesting the existence of one (or more) long-run relationships (cointegration) linking together our set of innovative capability and absorptive capacity variables.

\section{< Table 1 and table 2 here >}

As explained in the previous section, the crucial steps of our empirical methodology are the third and the fourth, where we estimate this long-term relationship and then analyse the direction of causality linking each pair of variables. The third step is the estimation of the vector correction model (VECM) specified in equation (6) (see derivation and intuition of this model in the previous section). The results of VECM estimations are presented in table 3. Notice that table 3 reports the results for a model with a 5-lag structure, although we have in addition run the same exercise for ten different lag specifications (from 1 to 10) in order to check for the robustness of the results.

Before discussing the results, it is important to notice that in the final specification presented in table 3 two of the absorptive capacity variables - social cohesion and quality of institutions have been included as exogenous variables in the model (and hence not reported in the table). The reason for this is that, in a preliminary estimation of the complete form of the model and in a set of Granger causality tests (available upon request), we noticed that these two factors, while having an impact on the other variables in our model, are not Granger-caused by any of the other factors, and it is therefore reasonable to regard them as exogenous factors in our final VECM specification. It is important to emphasize that the exogeneity of these two variables should not be interpreted as an indication that social and institutional factors are not important in our model, since they do indeed have an effect on the dynamics of the system. Rather, this means that our time series approach is not able to confirm any significant relationship 
explaining the drivers shaping these two factors over time, hence suggesting that their dynamics cannot simply be explained by the coevolution of innovation and absorptive capacity factors but it does probably entail the complex interplay of other dimensions (social, political, cultural) that are not accounted for in our model.

Turning to the VECM results in table 3, the most important are those presented in the first column under the heading "long run cointegration equation". These are the set of estimated parameters that identify a structural long-term relationship among our variables of interest, that is, in econometric terms, a linear combination of these variables that produce stationary residuals. The cointegration relationship reported in this column can be written as:

Technological output $=-386541,1$ (scientific output) $+65,94$ (innovative input $)+4,76$ (human capital $)+0,01$ (infrastructures) + 0,03 (income level) + 129,6 (international trade)

These results indicate the existence of a long-run equilibrium relationship according to which the dynamics of technological ouput (patents) is positively and significantly related to the growth of innovative input $(\mathrm{R} \& \mathrm{D})$ and the evolution of the four endogenous absorptive capacity variables included in this model (human capital, infrastructures, GDP per capita and openness to international trade).

It is interesting to observe, though, that the estimated long-run relationship between scientific and technological output turns out to have a negative coefficient, which contrasts with the typical expectation of a positive and self-reinforcing dynamics linking together scientific and technological activities (Dosi et al., 2006). One possible explanation for this peculiar finding is that the science-technology relationship may be characterized by different dynamics for countries at different levels of development, i.e. scientific production may be rapidly increased by means of public investments during the catching up phase of economic development, whereas technological output produced by private enterprises may become a more crucial driver of innovation systems as economies shift towards a more advanced development stage. Hence, when we focus on the time series perspective of the science-technology relationship, it is not unreasonable to expect that the two variables may be linked by a negative dynamic relationship over time.

The next column in table 3 reports the short-run adjustment coefficients, which confirm that most of the variables, when subject to external shocks (e.g. a policy change), tend to gradually readjust and go back to the long-term path identified by the cointegration equation. The only 
exception seems to be the innovative input variable, which shows a slight tendency to deviate permanently from its long-run path when subject to external shocks.

\section{< Table 3 here >}

The fourth and final step of our analysis is to investigate the direction of causality, i.e. to analyse, for each pair of variables included in the VECM model, whether they are related through a uni-directional type of causality $\left(\mathrm{Y}_{\mathrm{t}} \rightarrow \mathrm{X}_{\mathrm{t}}\right.$, or $\left.\mathrm{Y}_{\mathrm{t}} \leftarrow \mathrm{X}_{\mathrm{t}}\right)$ or rather by a bi-directional relationships $\left(\mathrm{Y}_{\mathrm{t}} \leftrightarrow \mathrm{X}_{\mathrm{t}}\right)$. In the latter case, we conclude that there is a coevolution of the two variables over time.

Table 4 presents the results of Granger block exogeneity tests based on the VECM model results discussed above here. The Granger tests have been repeated for ten different lags in order to check for the robustness of the results: only when at least five of the different lag specifications turn out to have significant results, we conclude that there is robust evidence of Granger causality (see last column on the right-hand side of the table). The table is divided in three parts, each of which referring to one of the three general propositions pointed out by our theoretical framework in section 3.

Further, to provide a more intuitive and more accessible presentation of these patterns, figure 3 shows a diagram that summarizes the main results of this causality analysis. The diagram has the same structure as our theoretical model (see figure 1, section 3), and it adds a set of arrows to show the causal relationship linking together each pair of variables (in this diagram, an arrow pointing in two (one) directions indicates evidence of a robust two-way (one-way) Granger causality relationship).

\section{Proposition 1. The internal dynamics of innovative capability.}

The first part of table 4 reports Granger block exogeneity tests referring only to the three innovative capability variables. These results provide clear support for the hypothesis that the link between input and output of the innovative process is a two-way relationship. On the one hand, the growth of $R \& D$ and innovative investments drives the dynamics of both scientific and technological output (input-output mechanisms). On the other hand, in turn, the growth of technological output sustains further $R \& D$ and innovative investments over time (cumulativeness of technological progress). It is this two-way self-sustaining relationship that explains the dynamics of innovation at the macro level. In short, these Granger test results provide empirical support for the first proposition formulated in section 3, and show that the 
internal dynamics of innovative capability is driven by the coevolution of the three main factors that define it, namely innovative input, scientific output and technological output.

\section{Proposition 2. The internal dynamics of absorptive capacity.}

The second panel of the table focuses on the four absorptive capacity variables (i.e. those included as endogenous factors in the final specification of our VECM model): infrastructures, human capital, income level and international trade. The Granger causality test results are in most cases significant and provide general support for the hypothesis that the dynamics of the absorptive capacity is driven by the coevolution of the various dimensions that define it. More precisely, we find support for the hypothesis of bi-directional causality for the three variables measuring income level, infrastructures and international trade, as shown in the bottom part of this table, i.e. these three factors coevolve together and support each other's dynamics over time. Interestingly, we do not find an analogous result for the human capital (tertiary education) variable. This does in fact Granger-cause the dynamics of income but does not seem to affect directly the growth of infrastructures and international trade. In other words, in our model the dynamics of human capital turns out to have an indirect effect on the evolution of absorptive capacity, i.e. by sustaining income growth (which in turn feeds back on the other three absorptive capacity variables).

\section{Proposition 3. The coevolution between innovative capability and absorptive capacity.}

The third part of table 3 then shifts the focus to the analysis of the mutual relationships between the innovative capability and the absorptive capacity variables. On the whole, the general result emerging from this table provides support for our third proposition, and indicates that innovative capability and absorptive capacity are linked together by a set of two-way dynamic relationships, i.e. they coevolve over time.

A more specific overview of the results points out the following patterns. (1) Technological output is linked by a two-way dynamic relationship to income per capita and infrastructures, but it is not directly related to human capital and international trade. (2) Scientific output coevolves with income per capita, infrastructures and international trade, and has a one-way causal effect on human capital dynamics. (3) Innovative input coevolves with infrastructures and international trade, it is driven by income dynamics (one-way relationship), but has no direct relationship to the human capital variable. (4) Similarly to what noticed in relation to proposition 2 above, the human capital (tertiary education) variable does not have any significant direct effect on the three innovative capability variables, but it rather plays an 
indirect role through its impacts on GDP per capita dynamics (which in turn feeds back and sustains the dynamics of all three innovative capability variables). This empirical result is in line with recent distance-to-frontier threshold models in which human capital is the key factor enabling imitation-based catching up (e.g. Howitt and Mayer-Foulkes, 2005; Iacopetta, 2010).

In a nutshell, a grand summary of our empirical results indicates that, over time, innovative capability and absorptive capacity factors are linked by a set of long-term structural relationships. Specifically, in our panel of countries for the period 1980-2008, the dynamics of national systems of innovation is driven by the coevolution of the three innovative capability variables, on the one hand, and the three absorptive capacity variables measuring income per capita, infrastructures and international trade, on the other. Further, human capital, the factor typically emphasized by most previous technology-gap and imitation-based growth models, turns out to have an indirect effect on the dynamics of the innovation system by sustaining the growth of GDP per capita and the country's absorptive capacity.

\section{< Table 4 and figure 3 here >}

\section{Conclusions}

The paper has argued that, in order to advance our analytical understandings and empirical measurement of how national systems of innovation evolve over time, a time series approach should complement the cross-country comparative perspective that has so far dominated most of the literature in the field of innovation and growth. In particular, by shifting the focus to the time series properties of the process of technological accumulation and economic development, the paper has put forward the stylized idea that the dynamics of national systems is driven by the coevolution of two main dimensions: innovative capability and absorptive capacity. On the one hand, the dynamics of the former sustains the growth of the latter, because innovative efforts and investments tend to increase countries' imitation capabilities as well as the pool of resources that can be reinvested in technological activities in the future. On the other hand, the evolution of a country's absorptive capacity may in turn sustain the dynamics of innovation by enhancing the productivity of the R\&D sector and the country's policy commitment to technological activities.

In order to explore this new direction of research, we have made use of a set of indicators measuring national innovative capabilities and absorptive capacity for a panel of 98 countries 
in the period 1980-2008. Our empirical methodology is rooted in the panel cointegration approach, which represents a recent extension of the time series cointegration analysis of nonstationary variables to the panel data context. Our empirical operationalization of the concept of coevolution is twofold: first, we investigate the existence of a long-run structural relationship (cointegration) among our set of innovative capability and absorptive capacity variables; secondly, for each pair of variables, we analyse the direction of causality by means of Granger block exogeneity tests. For those variables for which we find robust evidence of a two-way dynamic relationship, we conclude that a process of coevolution among these factors is at stake.

The empirical results indicate that innovative capability and absorptive capacity variables are indeed linked by a set of long-term structural relationships over the period 1980-2008. Specifically, the dynamics of national systems of innovation appears to be driven by the coevolution of two sets of factors: the three innovative capability variables (technological output, scientific output, innovative input), on the one hand, and three of the absorptive capacity factors (income per capita, infrastructures and international trade), on the other. Further, human capital (measured by tertiary education), the factor typically emphasized by most previous technology-gap and imitation-based growth models, does not turn out to have a direct effect on the dynamics of innovation activities and results, but rather an indirect effect by sustaining the growth of GDP per capita (which in turn feeds back and sustains the innovation dynamics over time).

We conclude by pointing out two main limitations and possible future refinements of our approach. First, an important element is missing in our operationalization of the concept of coevolution, namely structural change. When new technological paradigms emerge, the radically new nature and pervasiveness of emerging GPTs introduces disruptive change and transformations in the dynamics of innovative capability and absorptive capacity. This type of structural breaks has potentially important effects on the working of a cointegration and error correction time series model like the one presented in this paper (Foster and Wild, 1999). This problem is arguably of little relevance in the context of a relatively short time span like the one considered in this work, since the investigation period used here by and large represents a relatively stable long-run growth phase related to the emergence and diffusion of the ICT technological paradigm. However, when confronted with a longer time frame, the set of dynamic relationships among innovation and absorptive capacity variables would certainly be affected by technological shocks and episodes of structural and disruptive change, and this 
should be taken into account in future research by means of an appropriate time series analysis of structural breaks and the response of the variables to external shocks.

Secondly, the focus of our paper has been on the working of the model for the whole sample of countries, and we have not considered explicitly the possible existence of multiple patterns and regimes in our heterogeneous sample of countries. In econometric terms, the panel cointegration approach takes into due account the issue of cross-country heterogeneity by including fixed effects and country-specific time trends in the specification. However, our interpretation of the results has focused on the overall dynamic relationship between innovative capability and absorptive capacity, without an explicit investigation of how different country clubs may differ with respect to the set of identified relationships. It would therefore be interesting to extend this approach and investigate how and why countries differ in terms of their ability to shift from an imitation to an innovation development stage. We intend to consider these challenging issues and possible refinements of our approach in future research.

\section{Acknowledgments}

This paper was presented at the Globelics Academy in Tampere, May 2011. We wish to thank all the participants for stimulating comments and discussions. We are also grateful for the useful insights and suggestions received from Isabel Alvarez, John Foster and Manuel Godinho. The usual disclaimers apply. The authors acknowledge the financial support received from the Norwegian Research Council under the BITE project.

\section{References}

Abramovitz, M. (1986): "Catching-up, forging ahead and falling behind", Journal of Economic History, 46: 385-406.

Abramovitz, M. (1994): "The origins of the postwar catch-up and convergence boom", in Fagerberg, J., Verspagen, B. and von Tunzelmann, N. (Eds): The Dynamics of Technology, Trade and Growth, Edward Elgar, Aldershot.

Acemoglu, D., Aghion, P. and Zilibotti, F. (2006): "Distance to frontier, selection and economic growth", Journal of the European Economic Association, 4 (1): 37-74.

Archibugi, D. and Coco, A. (2004): "A new indicator of technological capabilities for developed and developing countries (ArCo)", World Development, 32 (4): 629-654. 
Arocena, R. and Sutz, J. (2003): "Inequality and innovation as seen from the South", Technology in Society, 25: 171-182.

Azariadis, C. and Drazen, A. (1990): "Threshold Externalities In Economic Development", Quarterly Journal of Economics, 105(2): 501-526.

Benhabib, J. and Spiegel, M. (1994): "The role of human capital in economic development. Evidence from aggregate cross-country data." Journal of Monetary Economics, 34: 143-173.

Breitung, J. and Pesaran, M. H. (2008): "Unit roots and cointegration in panels", in Matyas, L., Sevestre, P. (Eds.), The Econometrics of Panel Data: Fundamentals and Recent Developments in Theory and Practice, Kluwer Academic Publishers.

Castellacci, F. (2007): "Evolutionary and new growth theories. Are they converging?",_Journal of Economic Surveys, 21 (3): 585-627.

Castellacci, F. (2008): “Technology clubs, technology gaps and growth trajectories”, Structural Change and Economic Dynamics, 19 (4): 301-314.

Castellacci, F. (2011): “Closing the technology gap?”, Review of Development Economics, 15 (1): 180-197.

Castellacci, F. and Natera, J. M. (2011): "A new panel dataset for cross-country analyses of national systems and development (CANA)", Innovation and Development, 1 (2), in press.

Costantini, V. and Martini, C. (2010): "The causality between energy consumption and economic growth: a multi-sectoral analysis using non-stationary cointegrated panel data", Energy Economics, 32: 591-603.

Dosi, G., Llerena, P. and Sylos Labini, M. (2006): "The relationships between science, technology and their industrial exploitation: an illustration through the myths and realities of the so-called 'European Paradox', Research Policy, 35: 1450-1464.

Edquist, C. and Hommen, L. (2008): Small Country Innovation Systems: Globalisation, Change and Policy in Asia and Europe, Edward Elgar.

Engle, R. F. and Granger, C. W. J. (1987): "Cointegartion and error-correction: representation, estimation and testing”, Econometrica, 55: 251-276.

Esfahani, H. S. and Ramirez, M. T. (2003): "Institutions, infrastructure and economic growth", Journal of Development Economics, 70: 443-477.

Fagerberg, J. (1994): "Technology and International differences in growth rates", Journal of Economic Literature, 32: 1147-1175.

Fagerberg, J. and Verspagen, B. (2002): "Technology-gaps, innovation-diffusion and transformation: an evolutionary interpretation", Research Policy, 31: 1291-1304.

Fagerberg, J., Srholec, M. and Knell, M. (2007): "The competitiveness of nations: why some countries prosper while others fall behind", World Development, 35 (10): 1595-1620. 
Fagerberg, J., and Srholec, M. (2008): "National innovation systems, capabilities and economic development", Research Policy, 37: 1417-1435.

Filippetti, A. and Peyrache, A. (2011): "The Patterns of Technological Capabilities of Countries: A Dual Approach using Composite Indicators and Data Envelopment Analysis", World Development, in press.

Foster, J. (1991): "Econometric methodology in an environment of evolutionary change", in Saviotti and Metcalfe (Eds.), Evolutionary Theories of Economic and Technological Change: Present Status and Future Prospects, Harvood Academics, Reading.

Foster, J. and Wild, P. (1999): "Econometric modelling in the presence of evolutionary change", Cambridge Journal of Economics, 23: 749-770.

Freeman, C. (2004): "Technological infrastructure and international competitiveness", Industrial and Corporate Change, 13 (3): 541-569.

Furman, J., Porter, M. and Stern, S. (2002): "The determinants of national innovative capacity", Research Policy, 31: 899-933.

Galor, O. (2005): "From Stagnation To Growth: Unified Growth Theory", in P. Aghion, S.N. Durlauf (eds.), Handbook of Economic Growth, vol. 1A, London: Elsevier.

Galor, O. and Weil, D. (2000): "Population, technology and growth: from Malthusian stagnation to the demographic transition and beyond", American Economic Review 110: 806828.

Godinho, M.M., Mendonca, S.F., Pereira, T.S. (2006): “Towards a Taxonomy of Innovation Systems", mimeo, Universidade Tecnica de Lisboa.

Gong, G. and Keller, W. (2004): "Convergence and polarization in global income levels: a review of recent results on the role of international technology diffusion", Research Policy, 32: 1055-1079.

Honaker, J. and King, G. (2010): "What to do about missing values in time-series cross-section data", American Journal of Political Science, 54 (2): 561-581.

Howitt, P. (2000): "Endogenous growth and cross-country income differences", American Economic Review, 90 (4): 829-846.

Howitt, P. and D. Mayer-Foulkes (2005): "R\&D, implementation and stagnation: a Schumpeterian theory of convergence clubs", Journal of Money, Credit and Banking 37 (1): 147-177.

Iacopetta, M. (2010): "Phases of economic development and the transitional dynamics of an innovation-education growth model”, European Economic Review, 54: 317-330.

Krammer, S. (2010): "International R\&D spillovers in emerging markets: the impact of trade and foreign direct investment", Journal of International Trade and Economic Development, 19 (4): 591-623. 
Lundvall, B. A. (2007): "National innovation systems - analytical concept and development tool, Industry and Innovation, 14 (1): 95-119.

Lundvall, B. Å., Joseph, K., Chaminade, C. and Vang, J. (2009): Handbook on Innovation Systems and Developing Countries: Building Domestic Capabilities in a Global Setting, Edward Elgar.

Nelson, R. R. (1993): National Innovation Systems: A Comparative Analysis, Oxford University Press, New York and Oxford.

Papageorgiou, C. (2002): "Technology adoption, human capital and growth theory." Review of Development Economics, 6: 351-368.

Romer, P. (1990): "Endogenous technological change", Journal of Political Economy, 98: S71S102.

Stokke, H. (2008): "Productivity growth and organizational learning." Review of Development Economics, 12 (4): 764-778.

Varsakelis, N. (2006): "Education, political institutions and innovative activity: a cross-country empirical investigation", Research Policy, 35: 1083-1090.

Verspagen, B. (1991): “A new empirical approach to catching up or falling behind", Structural Change and Economic Dynamics, 2 (2): 488-509.

Weinhold, D. and Nair-Reichert, U. (2009): "Innovation, inequality and intellectual property rights", World Development, 37 (5): 889-901.

\section{Appendix 1: List of countries included in the sample}

Algeria, Argentina, Armenia, Australia, Austria, Azerbaijan, Belgium, Bolivia, Botswana, Brazil, Bulgaria, Burkina Faso, Cambodia, Canada, Chile, China, Colombia, Costa Rica, Croatia, Czech Republic, Denmark, Ecuador, El Salvador, Estonia, Ethiopia, Finland, France, Georgia, Germany, Greece, Guatemala, Honduras, Hungary, Iceland, India, Indonesia, Iran, Ireland, Israel, Italy, Jamaica, Japan, Jordan, Kazakhstan, Latvia, Lesotho, Lithuania, Madagascar, Malaysia, Mauritius, Mexico, Mongolia, Morocco, Mozambique, Netherlands, New Zealand, Nicaragua, Norway, Pakistan, Panama, Paraguay, Peru, Philippines, Poland, Portugal, Romania, Senegal, Singapore, Slovakia, Slovenia, South Africa, Spain, Sri Lanka, Sweden, Switzerland, Tajikistan, Thailand, Trinidad and Tobago, Tunisia, Turkey, Uganda, Ukraine, United Kingdom, United States, Uruguay, Vietnam, Zambia. 
Table 1. Panel unit root tests

\begin{tabular}{|c|c|c|c|c|c|c|c|c|c|c|}
\hline Tests & Lags & Technological output & Scientific output & Innovative input & Human capital & Infrastructures & Income level & Internat. trade & Social cohesion & Quality of institutions \\
\hline \multirow{15}{*}{$L L C$} & 10 & $-2.02335 * *$ & $-16.9675 * * *$ & $-9.17579 * * *$ & $-11.4923 * * *$ & 14.7648 & 18.251 & $-15.7992 * * *$ & $-18.0473 * * *$ & $-11.3315 * * *$ \\
\hline & 9 & -13.3208 **** & $-26.496 * * *$ & $-19.1772 * * *$ & $-29.2089 * * *$ & 3.76228 & $-7.97593 * * *$ & $-19.8495 * * *$ & $-30.5446 * * *$ & $-18.539 * * *$ \\
\hline & 8 & $-18.2002 * * *$ & $-34.3494 * * *$ & $-21.1013 * * *$ & $-34.6669 * * *$ & $-6.41072 * * *$ & $-10.8161 * * *$ & $-28.6584 * * *$ & $-39.6137 * * *$ & $-24.3516 * * *$ \\
\hline & 7 & $-21.6692 * * *$ & $-37.2536 * * *$ & $-21.9705 * * *$ & $-34.3293 * * *$ & $-8.50726 * * *$ & $-12.98 * * *$ & $-30.5447 * * *$ & $-38.9804 * * *$ & $-23.6934 * * *$ \\
\hline & 6 & $-26.5434 * * *$ & $-40.5721 * * *$ & $-27.0694 * * *$ & $-36.1954 * * *$ & $-9.69914 * * *$ & $-14.954 * * *$ & $-30.5798 * * *$ & $-37.623 * * *$ & $-25.9195 * * *$ \\
\hline & 5 & $-28.7022 * * *$ & $-38.9816 * * *$ & $-29.0885 * * *$ & $-39.3175 * * *$ & $-11.0755 * * *$ & $-15.3902 * * *$ & $-33.238 * * *$ & $-41.3525 * * *$ & $-28.0696 * * *$ \\
\hline & 4 & $-32.1352 * * *$ & $-40.5627 * * *$ & $-31.9036 * * *$ & $-39.555 * * *$ & $-12.866 * * *$ & $-14.9865 * * *$ & $-33.5979 * * *$ & $-42.0246 * * *$ & $-29.4694 * * *$ \\
\hline & 3 & $-30.8239 * * *$ & $-40.1687 * * *$ & $-33.6715 * * *$ & $-39.943 * * *$ & $-13.3754 * * *$ & $-15.5465 * * *$ & $-34.1738 * * *$ & $-44.6887 * * *$ & $-29.1116 * * *$ \\
\hline & 2 & $-34.102 * * *$ & $-44.8848 * * *$ & $-36.1488 * * *$ & $-42.9027 * * *$ & $-15.5323 * * *$ & $-15.7742 * * *$ & $-35.1269 * * *$ & $-46.2573 * * *$ & $-30.734 * * *$ \\
\hline & 1 & $-40.629 * * *$ & $-47.526 * * *$ & $-37.4231 * * *$ & $-43.916 * * *$ & $-15.9565 * * *$ & $-15.4385 * * *$ & $-36.0546 * * *$ & $-50.3336 * * *$ & $-31.8557 * * *$ \\
\hline & 10 & 14.0891 & 1.55943 & 2.9854 & $-4.02993 * * *$ & 4.87359 & 18.7741 & $-5.46528 * * *$ & $-2.92171 * * *$ & $-3.12889 * * *$ \\
\hline & 9 & 7.27273 & $-6.74634 * * *$ & $-1.66324 * *$ & $-14.4426 * * *$ & 2.02206 & 15.4448 & $-6.54649 * * *$ & $-13.0379 * * *$ & $-11.4203 * * *$ \\
\hline & 8 & 7.54889 & $-13.1393 * * *$ & $-4.67278 * * *$ & $-19.3728 * * *$ & 7.00653 & 3.75067 & $-15.6824 * * *$ & $-21.3297 * * *$ & $-10.6714 * * *$ \\
\hline & 7 & 4.38151 & $-13.1011 * * *$ & $-5.90755 * * *$ & $-20.1553 * * *$ & 8.39696 & -0.38319 & $-16.4187 * * *$ & $-22.2989 * * *$ & $-10.0946 * * *$ \\
\hline & 6 & $-3.77737 * * *$ & $-15.3864 * * *$ & $-8.21418 * * *$ & $-19.3309 * * *$ & 8.77256 & -1.64357 & $-16.5621 * * *$ & $-20.5575 * * *$ & $-10.7284 * * *$ \\
\hline \multirow[t]{10}{*}{ Breit } & 5 & $-9.33763 * * *$ & $-15.5619 * * *$ & $-8.41635 * * *$ & $-20.6934 * * *$ & 8.84453 & $-4.01633 * * *$ & $-17.8781 * * *$ & $-24.1482 * * *$ & $-9.59712 * * *$ \\
\hline & 4 & $-10.0285 * * *$ & $-15.0559 * * *$ & $-10.0194 * * *$ & $-20.8472 * * *$ & 9.75051 & $-3.91371 * * *$ & $-17.8949 * * *$ & $-24.7031 * * *$ & $-9.68953 * * *$ \\
\hline & 3 & $-8.40225 * * *$ & $-15.6899 * * *$ & $-9.68855 * * *$ & $-20.8867 * * *$ & 9.45028 & $-4.16978 * * *$ & $-17.7594 * * *$ & $-26.135 * * *$ & $-9.57113 * * *$ \\
\hline & 2 & $-9.95484 * * *$ & $-18.8456 * * *$ & $-11.0156 * * *$ & $-22.3598 * * *$ & 9.46121 & $-4.63218 * * *$ & $-18.1551 * * *$ & $-25.8098 * * *$ & $-10.5907 * * *$ \\
\hline & 1 & $-13.4844 * * *$ & $-20.1358 * * *$ & $-11.7786 * * *$ & $-23.003 * * *$ & 9.35138 & $-4.01333 * * *$ & $-19.2134 * * *$ & $-27.6053 * * *$ & $-10.6478 * * *$ \\
\hline & 10 & $-26.378 * * *$ & $-32.4423 * * *$ & $-29.4011 * * *$ & $-27.8776 * * *$ & $-16.1461 * * *$ & -1.34172 & $-23.5429 * * *$ & $-32.4019 * * *$ & $-28.152 * * *$ \\
\hline & 9 & $-32.8349 * * *$ & $-36.7785 * * *$ & $-32.9803 * * *$ & $-39.2475 * * *$ & $-20.1786 * * *$ & $-10.2289 * * *$ & $-29.9342 * * *$ & $-40.7348 * * *$ & $-32.0341 * * *$ \\
\hline & 8 & $-34.4573 * * *$ & $-40.7526 * * *$ & $-34.855 * * *$ & $-41.8729 * * *$ & $-21.4394 * * *$ & $-11.2218 * * *$ & $-31.5615 * * *$ & $-46.6088 * * *$ & $-35.3213 * * *$ \\
\hline & 7 & $-37.3109 * * *$ & $-43.5746 * * *$ & $-36.1552 * * *$ & $-41.865 * * *$ & $-21.8206 * * *$ & $-13.1931 * * *$ & $-32.5088 * * *$ & $-46.3004 * * *$ & $-34.519 * * *$ \\
\hline & 6 & -40.4759 *** & $-46.1656 * * *$ & $-38.2632 * * *$ & $-43.1919 * * *$ & $-22.8197 * * *$ & $-14.1868 * * *$ & $-32.6549 * * *$ & $-46.4979 * * *$ & $-36.3288 * * *$ \\
\hline \multirow[t]{10}{*}{$I P S$} & 5 & $-41.2368 * * *$ & $-44.4981 * * *$ & $-40.0511 * * *$ & $-45.6103 * * *$ & $-23.39 * * *$ & $-14.0725 * * *$ & $-34.1429 * * *$ & $-49.0434 * * *$ & $-36.7005 * * *$ \\
\hline & 4 & $-44.4491 * * *$ & $-46.5267 * * *$ & $-41.2734 * * *$ & $-45.8636 * * *$ & $-24.5028 * * *$ & $-13.9207 * * *$ & $-34.0758 * * *$ & $-49.6534 * * *$ & $-36.7294 * * *$ \\
\hline & 3 & $-43.9761 * * *$ & $-45.3522 * * *$ & $-42.4915 * * *$ & $-46.0854 * * *$ & $-24.2549 * * *$ & $-14.0789 * * *$ & $-34.3812 * * *$ & $-51.1255 * * *$ & $-36.5205 * * *$ \\
\hline & 2 & $-46.56 * * *$ & $-49.1754 * * *$ & $-43.9416 * * *$ & $-47.6022 * * *$ & $-25.2658 * * *$ & $-14.336 * * *$ & $-34.6582 * * *$ & $-52.0883 * * *$ & $-36.8641 * * *$ \\
\hline & 1 & $-50.9812 * * *$ & $-50.7038 * * *$ & $-44.8407 * * *$ & $-48.2989 * * *$ & $-25.8555 * * *$ & $-13.9164 * * *$ & $-35.2283 * * *$ & $-54.6527 * * *$ & $-37.1226 * * *$ \\
\hline & 10 & $1285.11 * * *$ & $1611.85 * * *$ & $1289.87 * * *$ & $1182.82 * * *$ & $719.988 * * *$ & $402.385 * * *$ & $937.04 * * *$ & $1359.56 * * *$ & $1120.44 * * *$ \\
\hline & 9 & $1435.27 * * *$ & 1705.23 *** & $1410.74 * * *$ & $1648.1 * * *$ & 806.07 *** & $498.209 * * *$ & $1110.04 * * *$ & $1673.9 * * *$ & $1231.31 * * *$ \\
\hline & 8 & $1528.48 * * *$ & 1843.96 *** & 1441.21 *** & $1736.63 * * *$ & 869.681 **** & $529.457 * * *$ & $1158.01 * * *$ & $2022.12 * * *$ & $1329 * * *$ \\
\hline & 7 & $1581.43 * * *$ & $1916.9 * * *$ & $1435.44 * * *$ & $1714.53 * * *$ & $869.795 * * *$ & $557.42 * * *$ & $1199.49 * * *$ & $1966.31 * * *$ & $1288.11 * * *$ \\
\hline & 6 & $1710.56 * * *$ & $1990.16 * * *$ & $1509.98 * * *$ & $1746.76 * * *$ & $909.241 * * *$ & $579.455 * * *$ & $1195.89 * * *$ & $1970.31 * * *$ & $1351.29 * * *$ \\
\hline \multirow[t]{6}{*}{$A D F$} & 5 & $1757.5 * * *$ & 1789.77 *** & $1773.1 * * *$ & $1830.74 * * *$ & $929.127 * * *$ & $567.38 * * *$ & $1242.39 * * *$ & $2065.67 * * *$ & $1364.07 * * *$ \\
\hline & 4 & $1867.13 * * *$ & $2020.64 * * *$ & $1835.65 * * *$ & $1839.11 * * *$ & $973.436 * * *$ & $561.909 * * *$ & $1237.28 * * *$ & $2057.15 * * *$ & $1357.61 * * *$ \\
\hline & 3 & $1832.93 * * *$ & $1935.29 * * *$ & 1875.41 *** & $1847.77 * * *$ & $945.878 * * *$ & $567.651 * * *$ & $1252.04 * * *$ & $2160.02 * * *$ & $1343.18 * * *$ \\
\hline & 2 & $1915.34 * * *$ & $2116.63 * * *$ & $1927.96 * * *$ & $1915.61 * * *$ & $996.079 * * *$ & $570.771 * * *$ & $1263.44 * * *$ & $2212.75 * * *$ & $1350.97 * * *$ \\
\hline & 1 & $2096.64 * * *$ & $2182 * * *$ & $1971.53 * * *$ & $1939.12 * * *$ & $1003.92 * * *$ & $562.814 * * *$ & $1281.03 * * *$ & $2345.1 * * *$ & $1366.99 * * *$ \\
\hline & 10 & $10498.7 * * *$ & 6371.34 *** & $6026.4 * * *$ & $6094.23 * * *$ & 1402.72 *** & $565.105 * * *$ & 2257.17 *** & $10527 * * *$ & $3259.69 * * *$ \\
\hline \multirow{2}{*}{$P P$} & 9 & $10762.1 * * *$ & $6371.34 * * *$ & $6026.4 * * *$ & $6094.23 * * *$ & $1402.72 * * *$ & $565.105 * * *$ & $2257.17 * * *$ & $10527 * * *$ & $3259.69 * * *$ \\
\hline & 8 to 1 & $11298.8 * * *$ & $6371.34 * * *$ & $6026.4 * * *$ & $6094.23 * * *$ & 1402.72 *** & $565.105 * * *$ & 2257.17 *** & $10527 * * *$ & $3259.69 * * *$ \\
\hline
\end{tabular}

LLC: Levin, Lin \& Chu t; Breit: Breitung t-stat.; IPS: Im, Pesaran \& Shin W-stat.. Significance levels: *** 1\%; ** 5\%; *10\%. 
Table 2. Pedroni cointegration test

\begin{tabular}{|cccc|}
\hline & & & \\
& Max lags & Panel $^{1}$ & Group $^{2}$ \\
& & & \\
& 10 & $-11.06791 * * *$ & $-20.61702 * * *$ \\
& 9 & $-12.21187 * * *$ & $-20.03907 * * *$ \\
& 8 & $-11.52201 * * *$ & $-21.37576 * * *$ \\
& 7 & $-11.62827 * * *$ & $-20.28275 * * *$ \\
ADF tests & 6 & $-12.47312 * * *$ & $-21.68366 * * *$ \\
& 5 & $-10.98558 * * *$ & $-21.0046 * * *$ \\
& 4 & $-11.08149 * * *$ & $-21.32561 * * *$ \\
& 2 & $-9.506939 * * *$ & $-21.28846 * * *$ \\
& 1 & $-12.83119 * * *$ & $-22.65517 * * *$ \\
& & $-13.04044 * * *$ & $-22.74456 * * *$ \\
& & & \\
\hline
\end{tabular}

${ }^{1}$ Alternative hypothesis: common AR coefs. (within-dimension) ${ }^{2}$ Alternative hypothesis: individual AR coefs. (between-dimension) Significance levels: *** $1 \%$; ** 5\%; * $10 \%$. 
Table 3. Results of the estimation of the panel vector error correction model (VECM)

\begin{tabular}{|c|c|c|c|}
\hline & $\begin{array}{c}\text { Long Run } \\
\text { Cointegration } \\
\text { Equation }\end{array}$ & $\begin{array}{l}\text { Short Run } \\
\text { Adjustment } \\
\text { Coefficients }\end{array}$ & $\mathbf{R}^{2}$ \\
\hline Technological output & 1 & $\begin{array}{c}-0.002601 \\
{[-3.05628] * * *}\end{array}$ & 0.20306 \\
\hline Scientific output & $\begin{array}{c}386541.1 \\
{[3.24624] * * *}\end{array}$ & $\begin{array}{c}-1.21 \mathrm{E}-08 \\
{[-4.06239] * * *}\end{array}$ & 0.22112 \\
\hline Innovative input & $\begin{array}{c}-65.9453 \\
{[-1.91957] * *}\end{array}$ & $\begin{array}{c}0.0000472 \\
{[3.38174] * * *}\end{array}$ & 0.09114 \\
\hline Human capital & $\begin{array}{c}-4.76499 \\
{[-4.26781] * * *}\end{array}$ & $\begin{array}{l}-0.000558 \\
{[-1.34256]}\end{array}$ & 0.09089 \\
\hline Infrastructures & $\begin{array}{c}-0.013706 \\
{[-2.50704] * *}\end{array}$ & $\begin{array}{c}-0.079792 \\
{[-2.06034] * *}\end{array}$ & 0.18925 \\
\hline Income level & $\begin{array}{c}-0.031801 \\
{[-6.95572] * * *}\end{array}$ & $\begin{array}{c}-0.701127 \\
{[-9.3097] * * *}\end{array}$ & 0.55615 \\
\hline International trade & $\begin{array}{c}-129.5993 \\
{[-3.55468] * * *}\end{array}$ & $\begin{array}{c}-0.0000508 \\
{[-3.73755] * * *}\end{array}$ & 0.07938 \\
\hline
\end{tabular}

Exogenous variables: social cohesion; quality of institutions

Lags included: 5. Observations: 1914

T-statistics in brackets: *** $1 \%$ sig. level; $* * 5 \%$ sig. level; 
Table 4. The direction of causality: Results of Granger block exogeneity tests (based on the panel VECM multivariate model)

\section{I: The internal dynamics of innovative capability}

\begin{tabular}{|c|c|c|c|c|c|c|c|c|c|c|c|}
\hline Bivariate relationships & 1 & 2 & 3 & 4 & $\begin{array}{c}\text { Lags } \\
5\end{array}$ & 6 & 7 & 8 & 9 & 10 & $\begin{array}{l}\text { Granger } \\
\text { Causality }\end{array}$ \\
\hline Innovative input $\rightarrow$ Technological output & $21.32004 * * *$ & $21.73125 * * *$ & $22.39227 * * *$ & $36.12588 * * *$ & $37.01912 * * *$ & $42.67967 * * *$ & $34.48828 * * *$ & $19.75859 * *$ & $23.74301 * * *$ & $28.16435 * * *$ & Yes \\
\hline Technological output $\rightarrow$ Innovative input & $11.87908 * * *$ & $16.25183 * * *$ & $13.1056 * * *$ & $17.41765 * * *$ & $15.47013 * * *$ & $16.44623 * *$ & $23.6052 * * *$ & $33.8762 * * *$ & $38.81754 * * *$ & $38.73672 * * *$ & Yes \\
\hline Innovative input $\rightarrow$ Scientific output & 0.036102 & 1.870124 & 2.940938 & $11.91267 * *$ & $9.281638 * * *$ & $18.26053 * * *$ & $26.10059 * * *$ & 20.19472 *** & $15.38625 * * *$ & 14.68185 & Yes \\
\hline Scientific output $\rightarrow$ Innovative input & 0.002631 & 1.066683 & 1.465886 & 3.735813 & 7.63818 & 7.23319 & $12.12452 * * *$ & $14.57777 * * *$ & $14.84209 * * *$ & 13.01383 & No \\
\hline Scientific output $\rightarrow$ Technological output & 0.203064 & 0.083062 & $32.55151 * * *$ & $45.22873 * * *$ & $33.77283 * * *$ & $33.54489 * * *$ & $12.23937 * * *$ & $15.94935 * *$ & $15.30795 * * *$ & $28.15139 * * *$ & Yes \\
\hline Technological outout $\rightarrow$ Scientific output & $15.53658 * * *$ & $15.95845 * * *$ & $17.49611 * * *$ & $113.3195 * * *$ & $105.9351 * * *$ & $78.0666 * * *$ & $97.8214 * * *$ & $81.94637 * * *$ & $83.12255 * * *$ & $88.63197 * * *$ & Yes \\
\hline
\end{tabular}

\section{II: The internal dynamics of absorptive capacity}

\begin{tabular}{|c|c|c|c|c|c|c|c|c|c|c|c|}
\hline Bivariate relationships & 1 & 2 & 3 & 4 & $\begin{array}{c}\text { Lags } \\
5\end{array}$ & 6 & 7 & 8 & 9 & 10 & $\begin{array}{l}\text { Granger } \\
\text { Causality }\end{array}$ \\
\hline Infrastructures $\rightarrow$ Human capital & 0.071123 & $16.69059 * * *$ & 11.91476 *** & $12.25926 * *$ & $18.53966 * * *$ & $18.38033^{* * *}$ & $18.61766 * * *$ & $21.30625 * * *$ & $22.83197^{* * *}$ & $24.86613 * * *$ & Yes \\
\hline Human capital $\rightarrow$ Infrastructures & 0.489929 & 0.55542 & 1.70809 & 4.621779 & 4.476804 & 7.040358 & $15.49445 * *$ & $16.25869 * *$ & $16.48624 * * *$ & $17.20511 * * *$ & No \\
\hline Income level $\rightarrow$ Human capital & 2.063986 & $6.061931 * *$ & 4.638791 & 5.600141 & 5.821298 & 6.544538 & 5.12065 & 11.68177 & 10.60825 & 11.60882 & No \\
\hline Human capital $\rightarrow$ Income level & $3.55786 * * *$ & $4.877883 * * *$ & $11.23341 * *$ & $11.38932 * *$ & 8.882979 & $12.51592 * * *$ & $15.98829 * *$ & $19.37588 * *$ & $23.41289 * * *$ & $23.05119 * *$ & Yes \\
\hline International trade $\rightarrow$ Human capital & 0.979598 & 1.088267 & 1.357368 & 4.87415 & 4.974863 & 4.655067 & 9.309686 & 8.146294 & 6.569753 & 5.834467 & No \\
\hline Human capital $\rightarrow$ International trade & 1.139726 & 0.522869 & 0.641172 & 1.221106 & 5.969001 & 6.533309 & 8.430544 & 9.923185 & 12.32296 & 11.94279 & No \\
\hline Income level $\rightarrow$ Infrastructures & 25.65041 *** & $34.25309 * * *$ & 28.57497 **** & $31.39228 * * *$ & $35.38122 * * *$ & $47.09036^{* * *}$ & $48.16645 * * *$ & $45.07046 * * *$ & 41.79587 *** & 60.98583 *** & Yes \\
\hline Infrastructures $\rightarrow$ Income level & 0.586904 & 1.135882 & 1.3285 & $17.45814 * * *$ & $23.15759 * * *$ & $27.06655 * * *$ & $32.012 * * *$ & $42.1077 * * *$ & $55.55036 * * *$ & $49.22835 * * *$ & Yes \\
\hline International trade $\rightarrow$ Infrastructures & $3.164558 * * *$ & $6.559222 * *$ & $7.853657 * *$ & $8.434165 * * *$ & $9.544925 * * *$ & 10.58685 & 10.01712 & 12.65833 & 13.1928 & 10.53763 & Yes \\
\hline Infrastructures $\rightarrow$ International trade & 0.872482 & $20.8078 * * *$ & $23.40596 * * *$ & $28.41551 * * *$ & $30.3896 * * *$ & $30.51383 * * *$ & $38.36711 * * *$ & $43.12035 * * *$ & $45.83851 * * *$ & $49.54764 * * *$ & Yes \\
\hline International trade $\rightarrow$ Income level & $4.767861 * *$ & $4.611315 * * *$ & 5.343564 & $10.59495 * *$ & $11.70891 * *$ & $14.7163 * *$ & $22.36506 * * *$ & 12.26364 & 12.77808 & $18.92982 * *$ & Yes \\
\hline Income level $\rightarrow$ International trade & $5.250288 * *$ & $27.40494 * * *$ & $23.22531 * * *$ & $25.78274 * * *$ & $26.91603 * * *$ & $22.18023 * * *$ & $32.72833 * * *$ & $33.48354 * * *$ & $38.85942 * * *$ & $48.48927 * * *$ & Yes \\
\hline
\end{tabular}


III: The coevolution between innovative capability and absorptive capacity

\begin{tabular}{|c|c|c|c|c|c|c|c|c|c|c|c|}
\hline \multirow{2}{*}{ Bivariate relationship } & \multicolumn{10}{|c|}{ Lags } & \multirow{2}{*}{$\begin{array}{c}\text { Granger } \\
\text { Causality }\end{array}$} \\
\hline & 1 & 2 & 3 & 4 & 5 & 6 & 7 & 8 & 9 & 10 & \\
\hline Human capital $\rightarrow$ Technological output & 1.572668 & 3.076869 & 4.726231 & 4.442304 & 5.729322 & 8.255578 & $15.90776 * *$ & 9.519367 & 10.19224 & 11.55729 & No \\
\hline Technological output $\rightarrow$ Human capital & 0.116183 & 0.0868 & $6.676459 * * *$ & 5.934444 & 6.151916 & 8.323827 & 7.516473 & 9.191246 & 11.14129 & 11.905 & No \\
\hline Infrastructures $\rightarrow$ Technological output & $16.20851 * * *$ & $8.596289 * *$ & 6.534365 *** & 5.844345 & 8.777307 & 7.310487 & $13.65961 * * *$ & $19.24805 * *$ & $34.44249 * * *$ & $39.67968 * * *$ & Yes \\
\hline Technological output $\rightarrow$ Infrastructures & 0.132594 & 2.3588 & 3.502463 & $17.66325 * * *$ & $45.89948 * * *$ & $59.13195 * * *$ & $45.58645 * * *$ & $44.28836 * * *$ & $30.76277 * * *$ & $31.45328 * * *$ & Yes \\
\hline Income level $\rightarrow$ Technological output & $4.414636 * *$ & 0.978824 & 5.077208 & $9.728226 * *$ & $38.28156 * * * *$ & $43.02793 * * *$ & $41.53666 * * *$ & $50.05825 * * *$ & $62.9281 * * *$ & $64.31709 * * *$ & Yes \\
\hline Technological output $\rightarrow$ Income level & 1.90049 & 1.606446 & 3.10514 & 6.002983 & 8.66107 & $10.95496 * * *$ & $22.4891 * * *$ & $28.79514 * * *$ & $34.47383 * * *$ & $46.85428 * * *$ & Yes \\
\hline International trade $\rightarrow$ Technological output & 0.039558 & 0.39889 & 0.319335 & 0.389719 & 2.451047 & 2.443907 & 4.900947 & 3.370879 & 1.954779 & 2.896627 & No \\
\hline Technological output $\rightarrow$ International trade & 0.551105 & 2.645379 & 2.127481 & 2.621795 & 3.322556 & 3.769297 & 5.612922 & 11.99803 & $17.22806 * *$ & $18.33334 * *$ & No \\
\hline Human capital $\rightarrow$ Scientific output & 2.541942 & $6.387079 * *$ & $7.881292 * *$ & 2.786648 & 6.077008 & 5.834888 & 6.55155 & 12.52758 & 12.87578 & $16.22468 * * *$ & No \\
\hline Scientific output $\rightarrow$ Human capital & 0.486708 & 3.178559 & $11.16304 * *$ & $15.63799 * * *$ & $12.15303 * *$ & 10.22731 & 9.941398 & 12.12528 & $15.10167 * * *$ & $24.0325 * * *$ & Yes \\
\hline Infrastructures $\rightarrow$ Scientific output & 0.04624 & 3.445991 & $19.17683 * * *$ & $13.07436 * *$ & $16.37265 * * *$ & $10.90182 * * *$ & $14.90601 * *$ & $31.92184 * * *$ & $35.0183 * * *$ & $35.6778 * * *$ & Yes \\
\hline Scientific output $\rightarrow$ infrastructures & $9.295721 * * *$ & $10.46055 * * *$ & $15.36708 * * *$ & $11.95016 * *$ & $38.71275 * * *$ & $69.56984 * * *$ & $65.7457 * * *$ & $41.6428 * * *$ & $44.48924 * * *$ & $51.46617 * * *$ & Yes \\
\hline Income level $\rightarrow$ Scientific output & $15.90829 * * *$ & $43.43056 * * *$ & $48.01339 * * *$ & $46.12999 * * *$ & $59.03562 * * *$ & $58.63725 * * *$ & $49.59162 * * *$ & $64.6799 * * *$ & $66.69526 * * *$ & $62.4862 * * *$ & Yes \\
\hline Scientific output $\rightarrow$ Income level & 2.150289 & 4.219628 & $7.658135 * * *$ & $9.199486 * * *$ & 6.651817 & 9.508092 & $22.12943 * * *$ & $17.29285 * *$ & $24.7555 * * *$ & $22.94525 * *$ & Yes \\
\hline International trade $\rightarrow$ Scientific output & 1.940913 & $12.10582 * * *$ & $7.055472 * * *$ & $8.774521 * * *$ & 6.935538 & $11.56188 * * *$ & $13.03969 * * *$ & 10.82183 & 12.73458 & 14.7039 & Yes \\
\hline Scientific output $\rightarrow$ International trade & $8.8065 * * *$ & $10.18745 * * *$ & $9.969457 * *$ & $12.07784 * *$ & $10.44513 * * *$ & 10.30247 & $20.22921 * * *$ & $16.52089 * *$ & $15.26703 * * *$ & $19.24827 * *$ & Yes \\
\hline Human capital $\rightarrow$ Innovative input & 0.049204 & 0.759877 & 1.622344 & 1.608096 & 5.023983 & 5.605948 & 5.348152 & 4.696185 & 7.294121 & 9.290443 & No \\
\hline Innovative input $\rightarrow$ Human capital & 0.022714 & 0.936654 & 5.855463 & 5.644463 & 5.04275 & 6.879506 & 6.942036 & 5.793254 & 7.89203 & 8.533766 & No \\
\hline Infrastructures $\rightarrow$ Innovative input & $20.55227 * * *$ & $26.67827 * * *$ & $24.41194 * * *$ & $21.38503 * * *$ & $20.91794 * * *$ & $21.42687 * * *$ & $20.49803 * * *$ & $16.59417 * *$ & $24.72358 * * *$ & $29.46254 * * *$ & Yes \\
\hline Innovative input $\rightarrow$ Infrastructures & $13.27583 * * *$ & $9.641964 * * *$ & $7.788195 * * *$ & $11.70094 * *$ & $14.34713 * *$ & $18.80563 * * *$ & $17.53996 * *$ & $20.1881 * * *$ & $27.00832 * * *$ & $26.32439 * * *$ & Yes \\
\hline Income level $\rightarrow$ Innovative input & $11.09302 * * *$ & $10.64323 * * *$ & $10.04898 * *$ & $12.95816 * *$ & $12.80222 * *$ & $14.4918 * *$ & $18.03748 * *$ & 8.728336 & 8.900332 & 7.422394 & Yes \\
\hline Innovative input $\rightarrow$ Income level & 1.440607 & 1.78745 & 3.964316 & $11.62674 * *$ & $11.07349 * *$ & 8.875249 & 10.67465 & $16.4007 * *$ & 13.15223 & 11.1774 & No \\
\hline International trade $\rightarrow$ Innovative input & $5.074378 * *$ & 8.950417 ** & $9.273583 * *$ & $14.50388 * * *$ & $13.55485 * *$ & $15.49662 * *$ & $14.99663 * *$ & 11.16334 & 11.99277 & 12.55653 & Yes \\
\hline Innovative input $\rightarrow$ International trade & 0.212552 & $5.940029 * * *$ & $7.628062 * * *$ & $8.538952 * * *$ & 7.590382 & 8.862783 & $13.82523 * * *$ & $15.33035 * * *$ & 12.54729 & 13.91522 & Yes \\
\hline
\end{tabular}


Figure 1. Theoretical framework: The coevolution of innovative capability and absorptive capacity

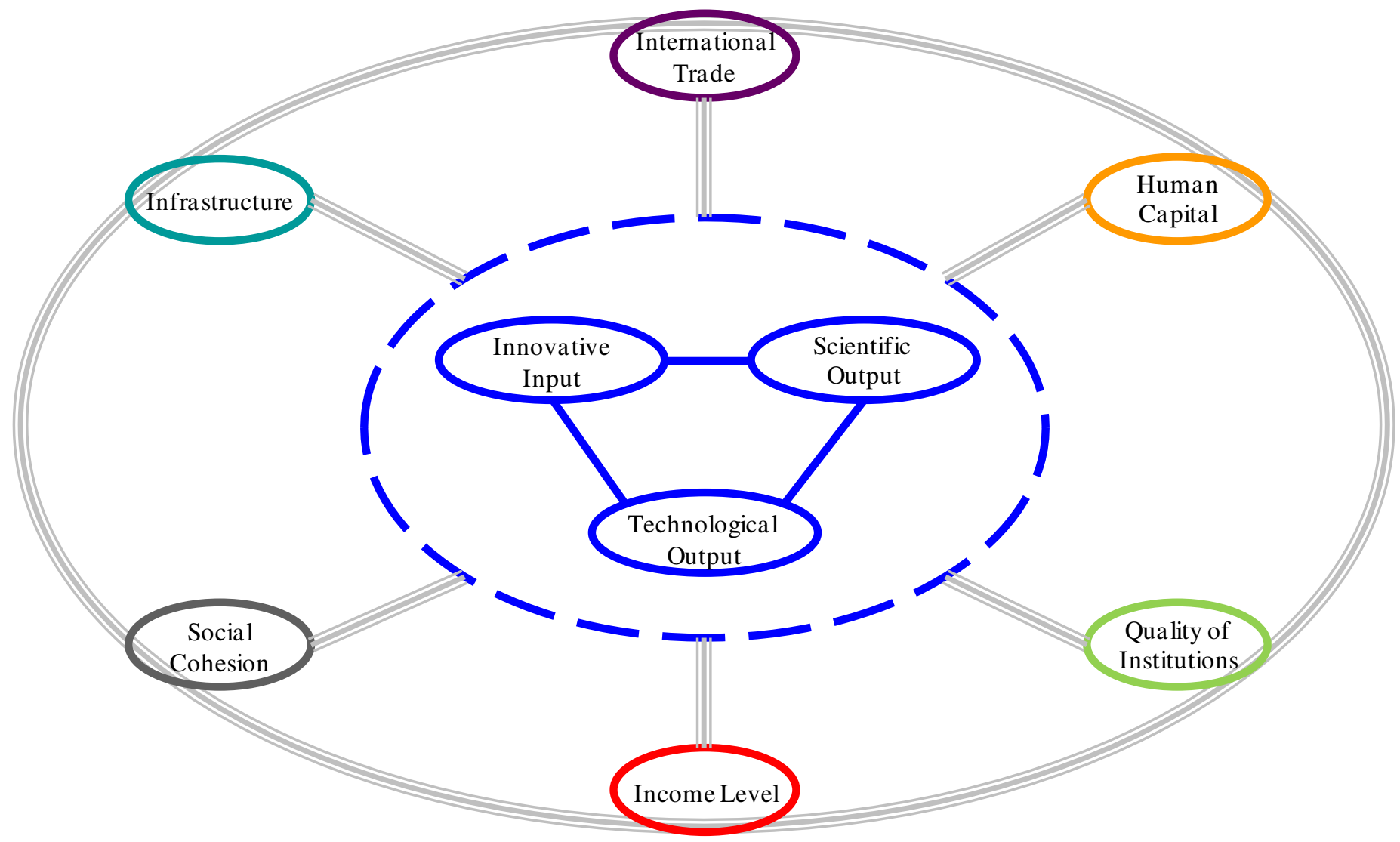

Innovative Capability

Absorptive Capacity 
Figure 2. Time series of the main variables (standardized) for six selected countries
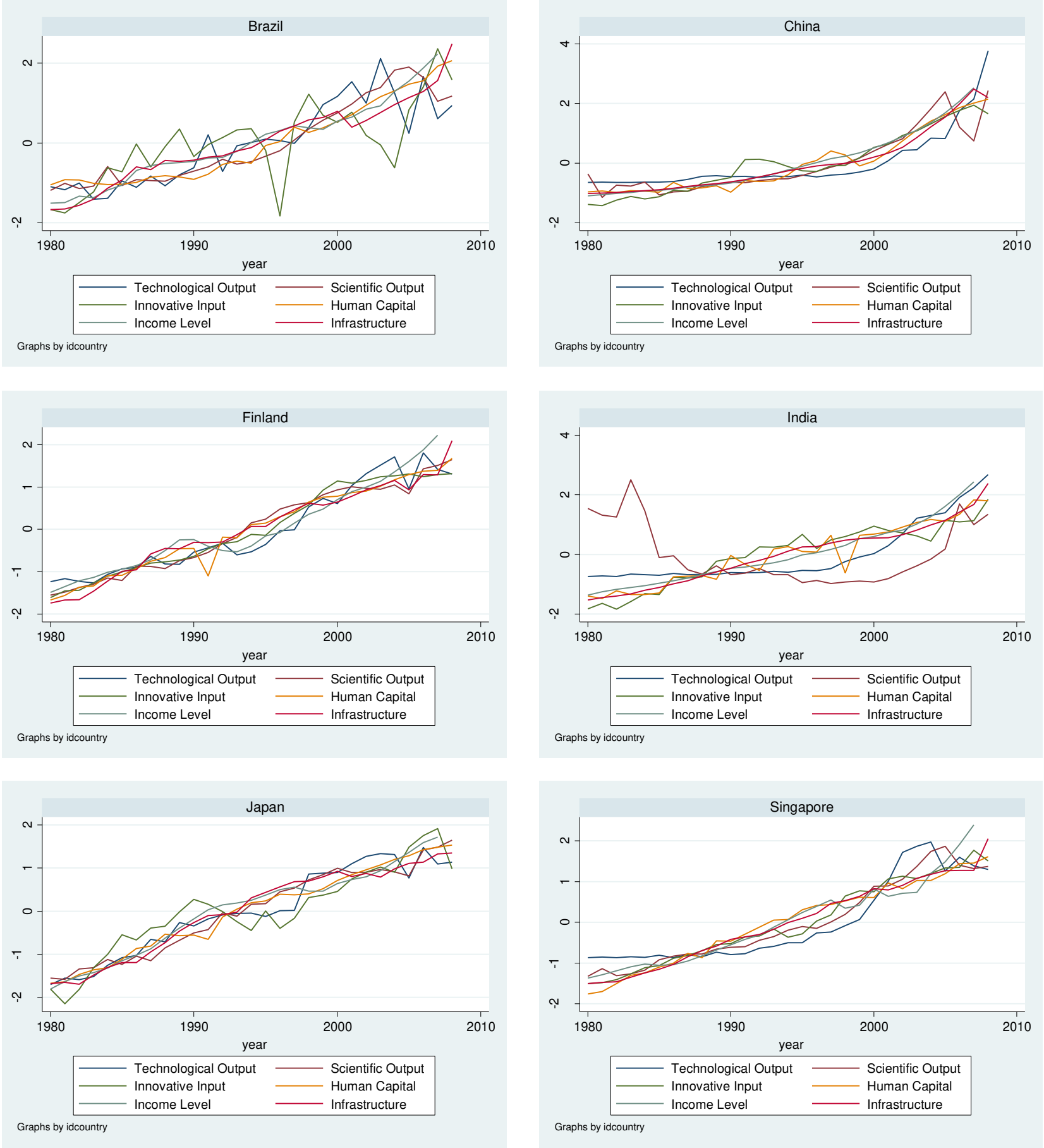
Figure 3. Summary of regression results: causal relationships and the coevolution of innovative capability and absorptive capacity

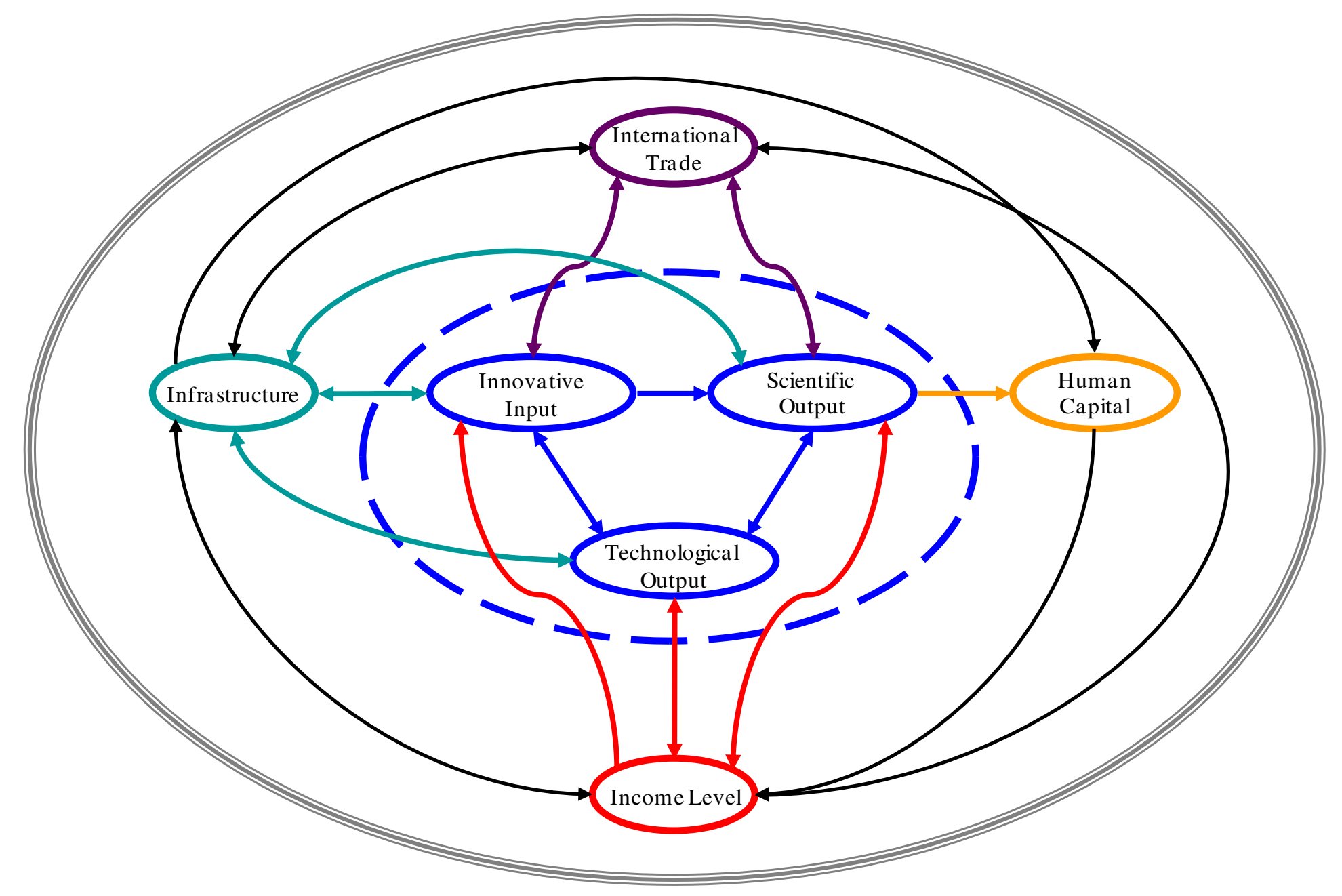

- Innovative Capability

Absorptive Capacity 